\title{
Screening for chlamydia: seize the day
}

\author{
Sarah Randall, D Scott LaMontagne
}

\section{Background}

Genital Chlamydia trachomatis is the commonest bacterial sexually transmitted infection in the UK, with the number of cases diagnosed in genitourinary medicine (GUM) clinics having increased continuously since the early 1990s to over 89000 in 2003, an $8 \%$ increase on the previous year. The prevalence in the UK has been reported between $2 \%$ and $29 \%$, depending on the testing site, population being tested and type of test. As expected, the highest rates of diagnoses are reported from GUM clinics and are among 16-19-year-old females (1334/100 000] and 20-24-year-old males $(961 / 100000) \cdot{ }^{1-4}$ It is estimated that approximately $70 \%$ of infections in women and $50 \%$ of infections in men are asymptomatic and therefore a large proportion of cases remain undiagnosed. Although easily treatable with oral antibiotics, most people remain untreated as they are unaware of their infection. Between $10 \%$ and $40 \%$ of untreated cases of chlamydia may develop pelvic inflammatory disease (PID) with the risk of long-term sequelae, namely ectopic pregnancy and infertility, being dependent on the number of PID episodes. Approximately $20 \%$ of infertility cases and $43 \%$ of ectopic pregnancies are said to be caused by chlamydia. ${ }^{5}$ Recent studies suggest chlamydial infections in men may impair a couple's ability to conceive, independent of the presence of tubal damage in the female partner. ${ }^{6}$ Research has postulated that chronic chlamydial infection may be a risk factor associated with reproductive tract cancers. 7,8

\section{Screening programme}

Although the natural history of chlamydia is incompletely understood, screening for chlamydia has been initiated and the place for screening has recently been reviewed by Low and Egger. ${ }^{9}$ There is also evidence from studies and programmes in North America and Sweden and theoretical modelling which has shown that targeted screening of atrisk populations is cost effective and can reduce morbidity. $10-14$

In England, screening was mentioned in the 1998 Chief Medical Officer's Expert Advisory Committee's report on Chlamydia trachomatis, which subsequently led to a variety of different projects. ${ }^{15}$ The Department of Health (DH) set up a 1-year pilot screening programme in Portsmouth and Wirral which confirmed the high prevalence of chlamydia outside GUM clinics, and the

J Fam Plann Reprod Health Care 2005; 31(2): 98-100

Ella Gordon Unit, St Mary's Hospital, Portsmouth and Department of Health, Sexual Health and Substance Misuse Team, London, UK

Sarah Randall, FRCOG, MFFP, Consultant in Reproductive Health and Medical Advisor to the Department of Health's National Chlamydia Screening Programme

HIV and STI Department, Health Protection Agency Centre for Infections, London, UK

D Scott LaMontagne, MPH, FRIPH, Clinical Scientist (Epidemiology)

Correspondence to: Dr Sarah Randall, Ella Gordon Unit, St Mary's Hospital, Portsmouth, PO3 6AD, UK

E-mail: jssimpson@btopenworld.com
Table 1 The National Chlamydia Screening Programme

\begin{tabular}{ll}
\hline Phase 1 & Phase 2 \\
\hline Camden and Islington & Birmingham \\
Cornwall & Brent and Harrow \\
Hull and East Riding & Brighton and Hove \\
Lambeth, Southwark and Lewisham & Cheshire East \\
Leeds & Cheshire West \\
Nottingham & Coventry \\
Portsmouth & Durham \\
Southend-on Sea & East Kent \\
Wirral & Enfield and Haringey \\
York & Liverpool \\
& Luton and Bedford \\
& Norfolk \\
& North and Mid-Hants \\
& Sheffield \\
& Slough \\
& Stoke \\
\hline
\end{tabular}

feasibility and acceptability of opportunistic screening using a urine test in a variety of health care settings. ${ }^{16}$ The National Survey of Sexual Attitudes and Lifestyles (NATSAL 2000) examined the behavioural factors associated with the infection and has provided the data used to estimate the size of the target population in each of the National Chlamydia Screening Programme (NCSP) areas. ${ }^{3,17}$ A study from Avon and the West Midlands undertook screening using postal specimens. ${ }^{18}$ In 2002 the $\mathrm{DH}$ also funded a study to examine risk factors associated with incidence and re-infection among screened individuals.

The start of the English NCSP was mentioned in the National Strategy for HIV and Sexual Health in July 2001 and in its Implementation Plan the following year. ${ }^{19}$ As a consequence, a multidisciplinary National Chlamydia Screening Steering Group (NCSSG) was formed in September 2002. The NCSP was to be introduced in phases, with the first 10 screening sites comprising Phase 1 identified in 2003. These sites had over 300 screening venues and a target population of 250000 . Phase 2 , with a further 16 sites, was introduced in January 2004, leading to a $25 \%$ coverage of all Primary Care Trusts (PCTs) in England with the plan to implement full coverage by 2008 (Table 1). The programmes received DH pump priming money for Year 1 and further funding for Years 2 and 3, after which all local programme costs are met by the PCTs. The subsequent publication of the DH's Public Health White Paper, 'Choosing Health', has stated that the programme will be accelerated with full coverage of the whole of England by 2007. ${ }^{20}$ Expressions of interest for Phase 3 are due to be published in early 2005. Also, late in 2004, the $\mathrm{DH}$ provided $£ 8$ million to all Strategic Health Authorities to ensure that all chlamydia testing could be undertaken using the more sensitive nucleic acid amplification tests (NAATs) rather than the older enzyme immunoassay tests. Non-invasive specimens (i.e. urine and low vaginal swabs) can be tested with NAATs. ${ }^{21}$

The aim of the NCSP is to offer screening to men and women under the age of 25 years who have ever been sexually active, using non-invasive specimens in a variety of heath and non-health care settings. Under 16-year-olds are included if deemed to be 'Fraser competent'.22 Treatment of those testing positive, together with partner 
notification, testing and treatment are a vital part of the programme. The NCSP's Core Requirements document, detailing the screening programme, is available on the DH website. ${ }^{23}$ The programme is unique in using a bespoke request form that is partially self-completed by the person being screened and for including two sexual behavioural questions for the first time in any screening programme. It should be noted that the information booklet and the use of these questions in the screening programme was approved by the Patient Information Advisory Group.

\section{Screening programme results}

Data from the first year of the programme have now been published. ${ }^{3}$ Over 16000 tests were performed outside GUM with $10 \%$ of screening undertaken in general practice and a further $10 \%$ in non-health care settings. The positivity was $10.1 \%$ in females and $13.3 \%$ in males and confirmed previous studies with the highest positivity being in 16-19-year-old women and 20-24-year-old men. The paper also confirmed the other risk factors for chlamydia, notably non-white ethnicity and a change in sexual partner (having had a new sex partner in the last 3 months or two or more sex partners in the last 12 months). The results of the patient management and partner followup, published in the NCSP's first Annual Report, showed a $98 \%$ treatment rate, that $90 \%$ of all partners were contacted by the patient themselves rather than a health advisor, and that $50 \%$ of patients testing positive and their partners were treated outside GUM either at the screening office or back at the original place of testing. ${ }^{24}$ Other studies have shown it is feasible to treat clients who test positive and undertake partner management outside GUM. 18,25,26 This is an important finding as it shows that patients appreciate having a choice of treatment venue and should also help allay fears that this programme will overwhelm already busy GUM services.

Frequency of screening is, as yet, unclear. The pilot ${ }^{2}$ was unable to address this issue but recommended an annual test with repeat screening following partner change, a policy that is included in the NCSP. The behavioural data from the first year of the NCSP is suggesting that some specific groups may need more frequent screening. ${ }^{3}$ The DH study on incidence and re-infection will add to this debate when published later this year.

\section{Future directions}

For prevalence within England to be reduced, there are key issues to be addressed: coverage targets must include all chlamydia tests, i.e. not only the under-25-year-old screening group but also diagnostic testing within GUM, and pre-instrumentation screening for termination of pregnancy and insertion of intrauterine devices, within this same age group; there must be high-volume screening within a site that is maintained over time; men must be 'targeted' as well as women; and a variety of different testing sites and modalities needs to be provided.

Screening within general practice proved very effective during the pilot, when there was a payment per test; but reassuringly in the first year of the NCSP, $10 \%$ of tests came from general practice with no payment. Barriers to screening within general practice are addressed in the NCSP core documents and include the use of a central screening office which co-ordinates the management of the person once a test has been taken, thereby reducing the workload on the test sites. ${ }^{23}$ A study of chlamydia testing in general practices in the Avon area found that 'high' testing sites had greater chlamydial awareness and a greater interest in sexual health. The authors suggested that knowledge, skills and attitudes would need to be addressed if all practices were to screen effectively. ${ }^{27}$ The introduction of the new general practitioner (GP) contract is affecting local practice and currently a template for a 'locally enhanced service' for chlamydia is being considered. A national survey of attendances at general practice surgeries in 1998 showed that $69 \%$ of men and $90 \%$ of women under 25 years of age saw their GP in the previous 12 months and that $28 \%$ of men and $53 \%$ of women had visited the practice nurse. ${ }^{28}$ This confirms that this venue is likely to be very important in achieving coverage.

Pharmacies, which have become an important adjunct in the provision of emergency contraception, may play a role, and several schemes are just starting to evaluate the place of high-street pharmacies in offering chlamydia screening and treatment. ${ }^{29}$ The NCSP has shown that over $10 \%$ of screening took place in non-health care settings (i.e. 'pee in a pot' days held in military bases, colleges and youth settings) and it is therefore important that these initiatives continue. The place of NHS Walk-in Centres has not yet been addressed, but several of the NCSP areas have them and an evaluation of these venues is expected in the near future. Postal kits may be a more acceptable option for certain groups, including men. ${ }^{30,31}$ Is there a role for a more formal 'recall' as with cervical smears? As the cervical cancer screening programme is increasing the age of the first smear from 20 to 25 years, could the first letter still be sent and invite the woman for a chlamydia screen rather than a cervical smear? The Wirral programme has decided to examine this possibility.

Whatever approach is taken, it is vital that chlamydia screening becomes a part of everyday life. So, for the under-25-year-old, having a test at least every year or on partner change will need to become a routine. As regards health care professionals, they will need to be trained to use any and every opportunity to offer a screen, not just at a sexual health consultation. Only in this way will adequate coverage be achieved and the prevalence of chlamydia reduced.

Statements on funding and competing interests

Funding. None identified.

Competing interests. None identified.

References

1 Health Protection Agency Centre for Infections. The UK Collaborative Group for HIV and STI Surveillance. Focus on Prevention. HIV and Other Sexually Transmitted Infections in the United Kingdom in 2003. London, UK: Health Protection Agency Centre for Infections, November 2004

2 Pimenta JM, Catchpole M, Rogers PA, Hopwood J, Randall S, Mallinson H, et al. Opportunistic screening for genital chlamydial infection II: Prevalence among health care attenders, outcome and evaluation of positive cases. Sex Transm Infect 2003; 79: 22-27.

3 LaMontagne DS, Fenton KA, Randall S, Anderson S, Carter P. Establishing the National Chlamydia Screening Programme in England: results from the first full year of screening. Sex Transm Infect 2004; 80: 335-341.

4 Adams EJ, Charlett A, Edmunds WJ, Hughes G. Chlamydia trachomatis in the United Kingdom: a systematic review and analysis of prevalence studies. Sex Transm Infect 2004; 80: 354-362.

5 Simms I, Stephenson JM. Pelvic inflammatory disease epidemiology: what do we know and what do we need to know? Sex Transm Infect 2000; 76: $80-87$.

6 Idahl A, Boman J, Kumlin U, Olofsson JI. Demonstration of Chlamydia trachomatis IgG antibodies in the male partner of the infertile couple is correlated with a reduced likelihood of achieving pregnancy. Hum Reprod 2004; 19: 1121-1126.

7 Ness RB, Goodman MT, Shen C, Brunham RC. Serologic evidence of past infection with Chlamydia trachomatis in relation to ovarian cancer. J Infect Dis 2003; 187: 1147-1152.

8 Paavonen J, Karunakaran KP, Noguchi Y, Anttila T, Bloigu A, Dillner $\mathrm{J}$, et al. Serum antibody response to the heat shock protein 60 of Chlamydia trachomatis in women with developing cervical cancer. Am J Obstet Gynecol 2003; 189: 1287-1292. 
9 Low N, Egger M. What should we do about screening for genital chlamydia? Int J Epidemiol 2002; 31: 891-893.

10 Addiss DG, Vaughn ML, Hillis SD, Ludka D, Amsterdam L, Davis JP. History and features of the Wisconsin Chlamydia trachomatis control program. Fam Plann Perspect 1994; 26: 83-86, 89.

11 Herrmann B, Egger M. Genital Chlamydia trachomatis infections in Uppsala County, Sweden, 1985-1993: declining rates for how much longer? Sex Transm Dis 1995; 22: 253-260.

12 Townsend JRP, Turner HS. Analysing the effectiveness of Chlamydia screening. J Oper Res Soc 2000; 51: 812-824.

13 Honey E, Augood C, Templeton A, Russell I, Paavonen J, Mardh PA, et al. Cost effectiveness of screening for Chlamydia trachomatis: review of published studies. Sex Transm Infect 2002; 78: 406-412.

14 Adams EJ, LaMontagne DS, Johnston AR, Pimenta JM, Fenton KA, Edmunds WJ. Modelling the healthcare costs of an opportunistic chlamydia screening programme. Sex Transm Infect 2004; 80: 363-370.

15 Chief Medical Officer's Expert Advisory Group. Main Report of the CMO's Expert Advisory Group on Chlamydia trachomatis. London, UK: Department of Health, 1998.

16 Pimenta JM, Catchpole M, Rogers PA, Perkins E, Jackson N, Carlisle $\mathrm{C}$, et al. Opportunistic screening for genital chlamydial infection I: Acceptability of urine testing in primary and secondary healthcare settings. Sex Transm Infect 2003; 79: 16-21.

17 Fenton KA, Korovessis C, Johnson AM, McCadden A, McManus S, Wellings $\mathrm{K}$, et al. Sexual behaviour in Britain: reported sexually transmitted infections and prevalence of genital Chlamydia trachomatis infection. Lancet 2001; 358: 1851-1854.

18 Low N, McCarthy A, Macleod J, Salisbury C, Horner PJ, Roberts TE, et al. The chlamydia screening studies: rationale and design. Sex Transm Infect 2004; 80: 342-348.

19 Department of Health. The National Strategy for Sexual Health and HIV. London, UK: Department of Health, July 2001

20 Department of Health. Public Health White Paper. Choosing Health: Making Healthy Choices Easier. London, UK: Department of Health, 2004. http://www.dh.gov.uk/PublicationsAndStatistics/Publications/ PublicationsPolicyAndGuidance/PublicationsPolicyAndGuidanceArt
icle/fs/en?CONTENT_ID=4094550\&chk=aN5Cor [Accessed 30 January 2004].

21 Chernesky MA. Chlamydia trachomatis diagnostics. Sex Transm Infect 2002; 78: 232-234.

22 Gillick v. West Norfolk and Wisbech AHA [1986] AC112, [1985] 3 WLR830, [1985] 3 All ER 402 HL.

23 Department of Health. National Chlamydia Screening Programme in England: Programme Overview, Core Requirements and Data Collection (2nd edn). London, UK: Department of Health, July 2004. http://www.dh.gov.uk/PolicyAndGuidance.

24 Department of Health. The First Steps: Annual Report of the National Chlamydia Screening Programme in England, 2003/04. London, UK: Department of Health, 2004.

25 Noone A, Spiers A, Allardice G, Carr S, Flett G, Brown A, et al. Opportunistic screening for genital Chlamydia trachomatis infection and partner follow-up in family planning clinics in three Scottish cities. J Fam Plann Reprod Health Care 2004; 30: 84-85.

26 Bacon L. Chlamydia testing in contraceptive clinics: who, where, how, why? J Fam Plann Reprod Health Care 2004; 30: 82-83.

27 McNulty CA, Freeman E, Bowen J, Shefras J, Fenton KA. Diagnosis of genital chlamydia in primary care: an explanation of reasons for variation in chlamydia testing. Sex Transm Infect 2004; 80: 207-211.

28 Airey C, Bruster S, Erens B, Lilley S-J, Pickering K, Pitson L. National Surveys of NHS Patients: General Practice 1998. London, UK: National Health Service Executive, 1999.

29 van Bergen JE, Postma MJ, Peerbooms PG, Spangenberg AC, TjenA-Tak J, Bindels PJ. Effectiveness and cost effectiveness of a pharmacy-based screening programme for Chlamydia trachomatis in a high-risk health centre population in Amsterdam using mailed home-collected urine samples. Int J STD AIDS 2004; 15: 797-802.

30 Stephenson J, Carder C, Copas A, Robinson A, Ridgway G, Haines A. Home screening for chlamydial genital infection: is it acceptable to young men and women? Sex Transm Infect 2000; 76: 25-27.

31 Østergaard L, Andersen B, Olesen F, Moller JK. Efficacy of home sampling for screening of Chlamydia trachomatis: randomised study. BMJ 1998; 317: 26-27.

\section{vasectomy services}

\section{Over 100,000 men have chosen us...}

making Marie Stopes International the country's most experienced vasectomy provider. With 20 centres nationwide we are able to offer a quick, reliable and straightforward service with no waiting lists.

For men who want the convenience of counselling, assessment and procedure on one day we offer a same day service. Our "non scalpel vasectomy technique" takes just a few minutes with no stitches and we provide all post operative aftercare and semen testing.

If you or your patient would like more information, simply call the number below and we will send further details.

\section{Call us on 08451203644 - 24 hours}

or visit www.mariestopes.org.uk

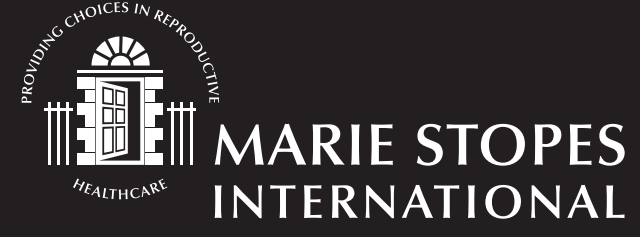

